\title{
Self-perceived mate value influences intrasexual competitiveness attitudes in young people of both sexes
}

\author{
PABLO POLO POLO ${ }^{1}$, JOSE ANTONIO MUNOZ-REYES $^{1 *}$, ANA MARIA FERNANDEZ TAPIA ${ }^{2}$, \\ JUAN ENRIQUE WILSON ${ }^{3}$ and ENRIQUE TURIÉGANO ${ }^{4}$
}

${ }^{1}$ Laboratorio de Comportamiento Animal y Humano, Centro de Estudios Avanzados, Universidad de Playa Ancha, Viña del Mar, Chile

${ }^{2}$ Escuela de Psicología, Universidad de Santiago de Chile, Santiago de Chile, Chile

${ }^{3}$ Departamento de Psicología, Universidad de Chile, Santiago, Chile

${ }^{4}$ Departamento de Biología, Universidad Autónoma de Madrid, España

(Received: 21 March 2018; accepted: 25 September 2018)

\begin{abstract}
Individuals vary in their intrasexual competitiveness attitude, i.e., an important variable reflecting the potential threat or the extent to which one perceives other individuals of the same sex as social or mating rivals. In this study, we investigated the relationship between self-perceived mate value, a construct usually linked to intersexual selection, and intrasexual competitiveness attitude. We postulated that those psychological traits that increase mate value are related to psychological traits underlying intrasexual competitiveness attitude. The results obtained from a sample of 711 young participants of both sexes $(M=16.93$ years $\pm \mathrm{SD}=0.86)$ indicated that mate value was positively related to intrasexual competitiveness attitude. Specifically, the subscales of Fear of Failure, Wealth, and Looks were positive predictors of intrasexual competitiveness attitude. Moreover, the Looks subscale was more relevant in determining intrasexual competitiveness attitude in women than in men. These three subscales were part of the same factorial structure that appears to be indicative of a self-promoting strategy based on the ostentation of traits through attitudes. As a conclusion, we argue that the individual differences in intrasexual competitiveness attitudes are associated with the differences in psychological features usually associated with intersexual selection.
\end{abstract}

Keywords: mate value, intrasexual competitiveness attitude, young people, sexual selection

\section{INTRODUCTION}

Intrasexual competition can be defined as competition between members of the same gender to gain reproductive access to the other (Darwin, 1871). Intrasexual competition has been extensively studied in human beings in terms of its behavioral mechanisms (e.g., Wilson \& Daly 1985; Fisher 2004; Archer 2009a; Fisher \& Cox 2009; Puts 2010; Vaillancourt 2013;), its relationship with physical traits (e.g., Fisher \& Cox, 2009; Muñoz-Reyes et al. 2012, 2015), and its evolutionary history (e.g., Buss 1989). The relative importance of intrasexual competition and the specific domains where competition occurs vary in relation to sex (Puts 2016). In men, contest competition is thought to be the predominant mechanism of intrasexual competition occurred during human evolutionary history (Archer 2009b). Accordingly, status, dominance, and resources are the primary domains of competition (Cashdan 1998). In women, competition to attract mates is thought to be the main mechanism of intrasexual competition (Fisher and Cox 2009; Vaillancourt 2013). This competition mainly functions through the enhancement of one's own attractiveness, although women also may exclude rivals by derogating their attractiveness (Vaillancourt 2013). Consequently, women mainly compete in physical attractiveness and, in a lesser degree, infidelity and trustworthiness (Cashdan 1998; Vaillancourt 2013). In addition to sex-differences in intrasexual competition, there are also both individual and sex differences in intrasexual competitiveness attitude, i.e., a variable reflecting the potential threat or the extent to which one perceives other individuals of the same sex as social or mating rivals (Buunk 2017; Buunk \& Fisher 2009; Hill et al. 2013). This variable is relevant to understand intrasexual competition, as a previous mental predisposition; however, it has been poorly studied in terms of psychological determinants of sexual selection, such as self-perception on mate value.

Mate value is a complex concept that was primarily defined in our species in terms of physical attractiveness, as demonstrated by the influence of different traits in human sexual selection, especially regarding intersexual - attrac-

*Author for correspondence. E-mail: jose.munoz-cea@upla.cl

This is an open-access article distributed under the terms of the Creative Commons Attribution-NonCommercial 4.0 International License (https://creativecommons.org/licenses/by-nc/4.0/), which permits unrestricted use, distribution, and reproduction in any medium for non-commercial purposes, provided the original author and source are credited, a link to the CC License is provided, and changes - if any - are indicated. 
tive - aspects (e.g., Grammer et al. 2003; Singh 2002). However, beyond physical attractiveness, there are several psychological traits that also determine mate value, such as ostentatious wealth, desire for children, or social abilities (Buss 2013; Fisher et al. 2008). Accordingly, mate value depends on two types of individual features: those that appear to inform others of a direct benefit of mating with bearers and those that offer indirect benefits through an increase in potential offspring fitness (Roberts \& Little 2008). Evolutionary psychologists contributed to the expansion of mate value beyond the realm of physical attractiveness by integrating psychological features into this concept, including self-esteem, mating attitudes, perceptions, and behaviors (e.g., Fisher et al. 2008). Many studies have reported positive relationships between mate value measures that include psychological aspects and different attractive sex-specific traits, linking mate value to a waistto-hip ratio (Singh 2002) and a body mass index (Fernandez, Muñoz-Reyes \& Dufey 2014) in women and to physical strength in men (Muñoz-Reyes et al. 2015). These results point toward the relevance of psychological aspects in human sexual selection processes and led to the redefinition of mate value as "the total sum of characteristics an individual possesses at a given moment and within a particular context that impacts on their ability to successfully find, attract, and retain a mate" (Fisher et al. 2008).

Mate value and intrasexual competitiveness attitude are mainly related to two different sexual selection mechanisms, that is, intersexual selection and intrasexual competition, respectively. Despite this, the self-perception of mate value is expected to be positively associated with the intensity of the intrasexual competitiveness through two main processes. First, individuals may compete against same-sex rivals for the access to sexual partners through the enhancement of one's own mate value (Vaillancourt, 2013). At the same time, individuals with high mate value are expected to be more demanding when looking for a mate (Edlund \& Sagarin 2010), more inclined to advertise their valuable traits (Sznycer et al. 2017), and consequently, it can be expected a higher degree of self-promoting intrasexual competition in those individuals. Second, some traits initially selected through intrasexual competition are employed as indicators of phenotypic quality by the other sex when selecting a mate (Berglund, Bisazza \& Pilastro 1996), becoming part of her/his mate value. Although mate value is equally defined for men and women, sexual differences in mate preferences have been reported (e.g., Buss 2013), suggesting that the components of mate value would affect intrasexual competitiveness attitude in a different way in each sex. In women, physical attractiveness is a highly valuable trait considered by men when choosing a partner (Buss \& Schmitt 1993; Feingold 1992), as a consequence, mate value traits related to physical attractiveness are expected to have a significant impact in intrasexual competitiveness in women (Puts 2010). In men, indicators of social status and resources are highly valued by women, especially when they are looking for a long-term relationship (Buss \& Schmitt 1993; Feingold 1992). Moreover, several aspects of mate value as fear of failure, sociality, and physical attractiveness are related to dominant behaviors and attitudes and are in turn preferred by women (Little, Jones \& Burriss 2007). For instance, the adoption of risky behaviors is a typical behavioral trait in young men (Wilson \& Daly 1985), and intrasexual competition among men was associated with elevated risk in competition during our evolutionary trajectory as a species (Puts 2010). In addition, facial masculinity and muscularity are physical characteristics that are attractive in a mate but that, in turn, are indicative of dominance and intrasexual competitiveness in men (Frederick \& Haselton 2007; Marcinkowska, Jasienska \& Prokop 2017). As a consequence, mate value traits related to social status, resources, and physical attractiveness are expected to have a major impact on intrasexual competitiveness in men.

The aim of this study was to test the hypothesis that self-perception of mate value affects the attitude of people to compete with members of the same sex in attracting mates. In doing this, we collected data of self-perceived mate value and intrasexual competitiveness attitude in a sample of Chilean participants of both genders between the ages of 16 and 23. Consequent with the hypothesis and considering the evidence reported above, we set out the following predictions.

1. We expect a positive relationship between a global measure of self-perceived mate value and intrasexual competitiveness attitude in both sexes. This will support the notion that individual variation in the psychological features affecting intrasexual competition is partially explained by self-perceived mate value.

2. In women, we expect to find a positive association between self-perceived mate value dimensions related to attractiveness (i.e., Looks and Views from the Opposite Sex) and intrasexual competitiveness attitude. In addition, we expect a positive association between parenting attitudes and desires (i.e., the Parenting dimension of mate value) and intrasexual competitiveness attitude, considering that women who are interested into having offspring would compete more intensely in attracting good sires.

3 . In men, we expect to find a positive association between mate value dimensions related to dominance, social status, and resource acquisition (i.e., Sociality and Wealth) and intrasexual competitiveness attitude. In addition, we expect that the mate value dimension related to Fear of Failure will be inversely related to intrasexual competitiveness attitude, indicating that men who have a lower level of apprehension about being rejected in the search for a partner will compete strongly in the intrasexual context. Finally, we also expect a relationship between dimensions of mate value related to physical attractiveness (i.e., Looks) and intrasexual competitive attitudes in men.

\section{MATERIAL AND METHODS}

\section{Participants}

We studied a sample of 711 participants of both sexes between 16 and 23 years of age (men: $N=343$, $M \pm \mathrm{SD}=17.00 \pm 0.87$ years; women: $N=368$, $16.87 \pm 0.86$ ) who were recruited from different locations. The younger participants were a sample of high school 
students from two schools located in Santiago de Chile. The adult participants were students from the Universidad de Santiago de Chile. Both processes of data collection were approved by the ethics committee of the Universidad de Playa Ancha and Universidad de Santiago de Chile. In addition, the studies were reviewed in their ethic issues by the ethics committee of the funding agency (i.e., FONDECYT, Chile). For the high school students, each legal tutor (usually the father or mother) gave consent for the student's participation. Adult participants were informed through a consent. In both samples and to protect privacy and facilitate the reliability of answers to questionnaires, each participant's data was considered only by a consecutive number assigned to the respective individual.

\section{Mate value psychometric measures}

At least 5 different scales have been proposed to holistically asses mate value, including psychological traits: the Mate Value Inventory (Kirsner, Figueredo, \& Jacobs 2003), the Mating Success Scale (Landolt, Lalumière \& Quinsey 1995), the Mate Value Single Item Scale (Brase \& Guy 2004), the Mate Value Scale (Edlund \& Sagarin 2014), and finally, the Mate Value Components (Fisher et al. 2008). All of these works are with the Likert scale, but they show several differences. The Mate Value Inventory (Kirsner et al. 2003) allows for self-assessment of the participant's mate value on several specific attributes that are valued in the mating arena (e.g., ambitiousness, physical attractiveness, health, etc.). The Mating Success Scale (Landolt et al. 1995) is considered to be a measure of selfesteem that is linked to mating, and it targets previously successful mating attempts. The Mate Value Single Item Scale (Brase \& Guy, 2004) and Mate Value Scale (Edlund \& Sagarin 2014) ask about the topics related to one's desirability as a partner (e.g., 'Overall, how would you rate your level of desirability as a partner?'). And finally, the Mate Value Components (MVC; Fisher et al. 2008) includes different dimensions of mate value, such as those considered in the Mating Success Scale and related to self-esteem (Landolt et al. 1995) and those considered in the Mate Value Scale and related to perceptions from the opposite sex (Edlund \& Sagarin 2014). The MVC also incorporates additional questions about current and past attitudes, perceptions, and behaviors that influence mate value (e.g., 'Members of the opposite sex that I like tend to like me back' and 'It is important that members of the opposite sex view me as a good parent'). This dimensionality is relevant, making the MVC a suitable proxy for mating attitudes and behavior, and for this reason, it was chosen in this study.

Participants completed a Chilean adaptation (Fernández et al. 2015) of the MVC questionnaire (Fisher et al. 2008). This questionnaire was composed of 22 items split into 7 subscales: Views from the Opposite Sex (6 items, e.g., 'Members of the opposite sex that I like tend to like me back'), Sociality (5 items, e.g., 'I run into friends wherever I go'), Looks (2 items, e.g., 'I would like members of the opposite sex to consider me physically attractive'), Relationship History (2 items, e.g., 'After I date someone they often want to date me again'), Fear of Failure (2 items, e.g., 'I often worry about not having a date'), Parenting (3 items, e.g., 'I want to have children in my lifetime'), and Wealth ( 2 items, e.g., 'I have a tendency to display my wealth'). Participants responded to the items on a 7-point Likert scale $(1=$ strongly disagree to $7=$ strongly agree $)$. The internal consistency of the present study was comparable to the original studies where the scale was applied (total mate value: $\alpha=0.87$, Views from the Opposite Sex: $\alpha=0.90$, Sociality: $\alpha=0.61$, Looks: $\alpha=0.88$, Relationship History: $\alpha=0.58$, Fear of Failure: $\alpha=0.61$, Parenting: $\alpha=0.74$, and Wealth: $\alpha=0.81$ ). For other samples, see Chilean population in the work of Fernandez et al. $2014(\alpha=0.85)$ and Canadian population in that of Fisher et al. $2008(\alpha=0.83)$.

\section{Intrasexual competitiveness attitude assessed from the intrasexual competition scale (ICS)}

We applied a Chilean adaptation of the original ICS (Buunk \& Fisher 2009). This adaptation is unpublished but has been employed in previous studies (e.g., Fernandez et al. 2014). The scale is composed of 12 items that assess the degree of competition with same-sex peers (e.g., 'I tend to look for negative characteristics in attractive women') and can be considered a measure of intrasexual competition as an attitude (Buunk \& Fisher 2009). Answers are given on a 7-point Likert scale ( $1=$ not applicable at all to $7=$ completely applicable). The internal consistency obtained in the present study was similar to that observed in other studies (in our study: $\alpha=0.84$; another Chilean sample from Fernandez et al. 2014: $\alpha=0.85$; Dutch and Canadian populations from Buunk $\&$ Fisher 2009: $\alpha=0.87$ and $\alpha=0.88$, respectively).

\section{Statistical analyses}

In the initial stage, we assessed sexual differences in intrasexual competitiveness attitude, mate value, and its dimensions with a $t$-test or the Mann-Whitney $U$ test depending on data distribution. To test the first prediction, we performed a simple linear regression for each sex, with intrasexual competitiveness attitude as the dependent variable, a global measure of mate value as the independent variable, and age as a control covariable. For the second and third predictions, we initially performed Spearman rho correlation tests between intrasexual competitiveness attitude and mate value subscales separately for each sex. Next, we conducted multiple linear regression analysis, including the mate value subscales and sex as the independent variables, age as a control covariable, and intrasexual competitiveness attitude as the dependent variable. We initially conducted the regression entering all variables followed by a stepwise adjustment. We performed an additional linear regression analysis including interactions of sex with the significant subscales retained from the previous analyses. We calculated tolerance values in the regression analyses to address possible multicollinearity between predictors (Dormann et al. 2013). Finally, to facilitate the interpretation of unexpected results, we conducted an exploratory factor analysis on the 7 subscales of the mate value component questionnaire. This analysis 
Table 1. Descriptive statistics and sexual differences in all of the variables (note: men $N=343$ and women $N=368$; ns = non-significant; $\mathrm{K}-\mathrm{S}=$ Kolmogorov-Smirnov)

\begin{tabular}{|c|c|c|c|c|}
\hline Variables & $\begin{array}{c}\text { Men } \\
M \pm S D\end{array}$ & $\begin{array}{l}\text { Women } \\
\mathrm{M} \pm \mathrm{SD}\end{array}$ & Comparison between sexes & Normality test $(\mathrm{K}-\mathrm{S})$ \\
\hline Intrasexual competitiveness attitude & $35.36 \pm 12.27$ & $34.70 \pm 12.64$ & $U=60710.50$ & $\begin{array}{c}D_{\text {men }}=0.041 \\
D_{\text {women }}=0.053^{*}\end{array}$ \\
\hline General Mate Value & $89.43 \pm 19.17$ & $81.91 \pm 20.57$ & $t_{(709)}=5.03^{* * *}$ & $\begin{array}{c}D_{\text {men }}=0.040 \\
D_{\text {women }}=0.043\end{array}$ \\
\hline Views from the opposite sex & $22.87 \pm 7.94$ & $23.53 \pm 8.48$ & $U=59231.50$ & $\begin{aligned} D_{\text {men }} & =0.044 \\
D_{\text {women }} & =0.077^{* * *}\end{aligned}$ \\
\hline Sociality & $21.66 \pm 5.61$ & $18.75 \pm 6.33$ & $U=45558.00^{* * *}$ & $\begin{array}{c}D_{\text {men }}=0.057^{*} \\
D_{\text {women }}=0.063^{* *}\end{array}$ \\
\hline Looks & $8.34 \pm 3.38$ & $7.40 \pm 3.60$ & $U=53639.00^{* *}$ & $\begin{array}{c}D_{\text {men }}=0.103^{* * *} \\
D_{\text {women }}=0.088^{* * *}\end{array}$ \\
\hline Relationship history & $8.82 \pm 2.97$ & $8.52 \pm 3.12$ & $U=59317.50$ & $\begin{array}{c}D_{\text {men }}=0.110^{* * *} \\
D_{\text {women }}=0.075^{* * *}\end{array}$ \\
\hline Fear of failure & $6.30 \pm 2.89$ & $4.95 \pm 2.69$ & $U=45375.50^{* * *}$ & $\begin{array}{c}D_{\text {men }}=0.097^{* * *} \\
D_{\text {women }}=0.143^{* * *}\end{array}$ \\
\hline Parenting & $16.95 \pm 4.49$ & $15.38 \pm 5.00$ & $U=50914.50^{* * *}$ & $\begin{array}{c}D_{\text {men }}=0.174^{* * *} \\
D_{\text {women }}=0.154^{* * *}\end{array}$ \\
\hline Wealth & $4.50 \pm 2.98$ & $3.39 \pm 2.17$ & $U=49372.50^{* * *}$ & $\begin{array}{c}D_{\text {men }}=0.211^{* * *} \\
D_{\text {women }}=0.316^{* * *}\end{array}$ \\
\hline 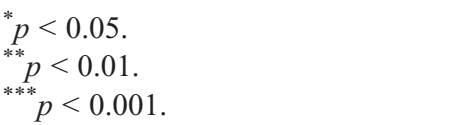 & & & & \\
\hline
\end{tabular}

allowed us to examine the internal structure of mate value. The relationships of the factors with intrasexual competitiveness attitude were also assessed with a linear regression analysis. We employed IBM SPSS 21 software, and the global levels of significance were set at $\alpha=0.05$.

\section{RESULTS}

Descriptive statistics, normality tests and tests of sex differences can be observed in Table 1. It is interesting to note that men reported higher values in all indicators in which there were significant differences. This result is indicative of higher (but not finer tuning) masculine self- perception in mate value. This result also indicated a higher Fear of Failure in men compared to women.

In the first prediction, we expected a positive relationship of mate value with intrasexual competitiveness attitude. The results from linear regression analyses (Figure 1) supported our prediction for both men (beta $=0.23$, $p<0.001$ ) and women (beta $=0.37, p<0.001)$. Therefore, when mate value increased, intrasexual competitiveness attitude increased too. Age was not related to intrasexual competitiveness attitude in any sex (men: beta $=-0.04, p=0.508$; women: beta $=0.03, p=0.521$ ).

In order to test the second and third predictions in which we expected sex-specific positive relationships between components of mate value with intrasexual competitiveness attitude, we initially performed a correlational
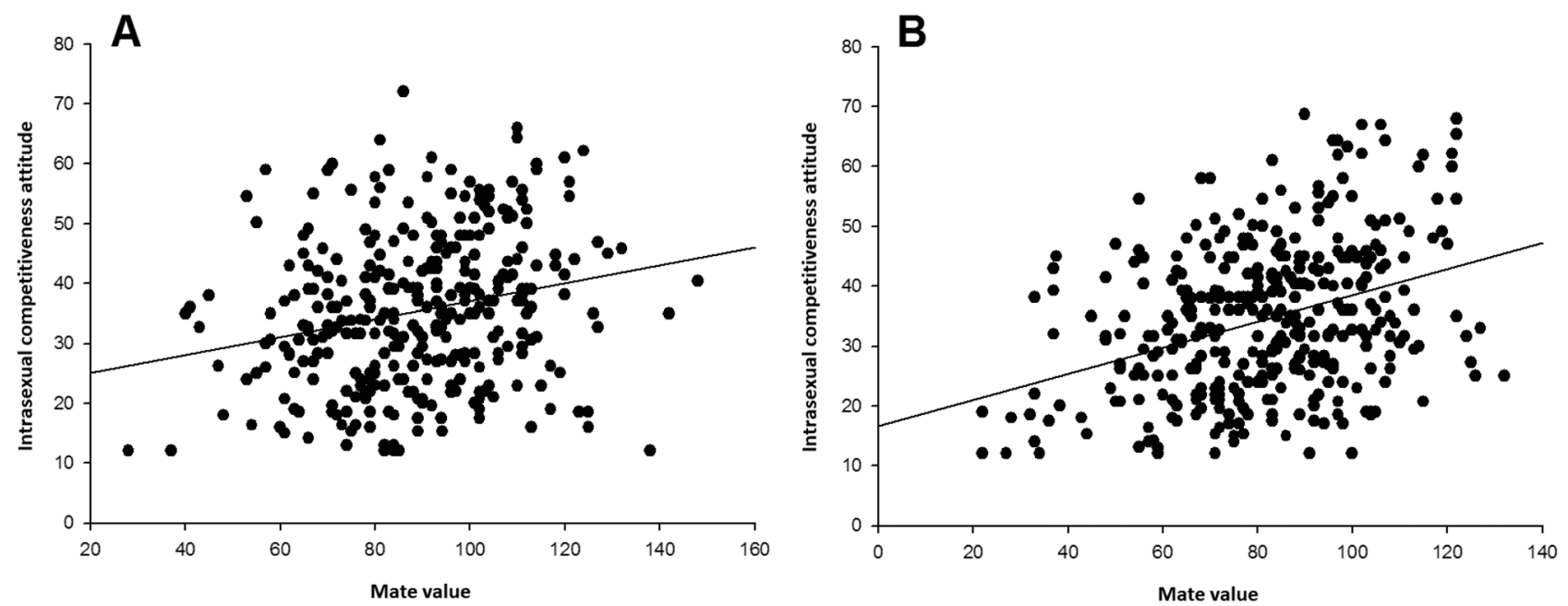

Figure 1. Scatterplots of the relationship between Mate Value, and Intrasexual Competitiveness attitude in men (A) and women (B) 
Table 2. Spearman correlations between intrasexual competitiveness attitude and mate value subscales in both sexes (note: men $N=343$ and women $N=368$ )

\begin{tabular}{ccc}
\hline Variables & Men & Women \\
\hline Views from the opposite sex & $\sigma_{(343)}=0.10$ & $\sigma_{(368)}=0.17^{* *}$ \\
Sociality & $\sigma_{(343)}=-0.01$ & $\sigma_{(368)}=0.13^{*}$ \\
Looks & $\sigma_{(343)}=0.28^{* * *}$ & $\sigma_{(368)}=0.40^{* * *}$ \\
Relationship history & $\sigma_{(343)}=0.13^{*}$ & $\sigma_{(368)}=0.18^{* * *}$ \\
Fear of failure & $\sigma_{(343)}=0.38^{* * *}$ & $\sigma_{(368)}=0.41^{* * *}$ \\
Parenting & $\sigma_{(343)}=0.06$ & $\sigma_{(368)}=0.19^{* * *}$ \\
Wealth & $\sigma_{(343)}=0.37^{* * *}$ & $\sigma_{(368)}=0.31^{* * *}$ \\
\hline
\end{tabular}

${ }_{* *}^{*}<0.05$.

${ }^{* *} p<0.01$

${ }^{* * *} p<0.001$.

analysis between intrasexual competitiveness attitude and the subscales of mate value (Table 2). The results indicated that, in both sexes, the mate value subscales were positively correlated with intrasexual competitiveness attitude, with the exclusion of Parenting, Views of the Opposite Sex, and Sociality in men. Next, a multiple linear regression analysis entering sex, age, and all the subscales of mate value as independent variables was performed (Table 3). The results indicated a significant association between sex and mate value subscales of Fear of Failure, Wealth, and Looks with intrasexual competitiveness attitude $\left(R^{2}=0.23, F(9,701)=23.11, p<0.001\right)$. These variables were retained when performing a stepwise selection procedure $\left(R^{2}=0.22, F(4,706)=50.86, p<0.001\right)$. The subscales of Parenting, Views from the Opposite Sex, Sociality, and Relationship History, as well as the covariable age, were eliminated from the model. Finally, we fitted a regression model including sex, the retained subscales (Fear of Failure, Looks and Wealth) and the interactions of each subscale with sex (Table 3 ). This fitted model was also statistically significant $\left(\mathrm{R}^{2}=0.23, \mathrm{~F}(6,704)=35.297\right.$, $\mathrm{p}<0.001)$. Among the interactions, only that of sex with Looks was retained after a stepwise analysis, indicating the presence of sex differences on the strength of the relationship between Looks and intrasexual competitiveness attitude. When analyzing betas for each sex, we noted that although the effect of the subscale of Looks was positive in both sexes, it was stronger in women than in men (see Figure 2). In all regression analysis, tolerance values (see tolerance in Table 4) supported the absence of multicollinearity problems (values $>0.01$ according to Dormann et al. 2013).

Finally, we ran an exploratory factor analysis in the mate value subscales. Table 4 shows the pattern matrix of this analysis (Maximum Likelihood extraction method, Promax rotation with Kaiser Normalization; ChiSquare $=26.25 ; p=0.001)$. The analysis yielded two factors (eigenvalues above 1.0) that together explained $58.8 \%$ of the total variance. As seen in Table 4, a clear solution was found, with Views from the Opposite Sex, Sociality, and Relationship History loading above 0.50 in the first factor (factor 1) and Fear of Failure, Wealth, and Looks loading above 0.50 in the second factor (factor 2). Moreover, none of these subscales had cross-loadings; however, Parenting loaded weakly into both factors. This result indicated that participants differentiated the mate value subscales into 2 major categories. Note that Fear of Failure was correlated with Wealth and Looks and that these 3 subscales were the only ones that were significantly related to intrasexual competitiveness attitude. We fitted a linear regression analysis in order to assess the relationships between factors and intrasexual competitiveness attitude. We included sex, age, factor 1 , factor 2 , and the interactions between factor 1 with sex and factor 2 with

Table 3. Multiple linear regression test between sex and mate value subscales as independent variables and intrasexual competitiveness attitude as the dependent variable (note: $\operatorname{men} N=343$, women $N=368$ )

\begin{tabular}{cclc}
\hline Method & Variables & Beta & Tolerance \\
\hline Enter & Sex & $0.10^{* *}$ & 0.84 \\
& Views from the opposite sex & -0.03 & 0.49 \\
& Sociality & -0.04 & 0.70 \\
& Looks & $0.16^{* * *}$ & 0.58 \\
& Relationship history & 0.06 & 0.51 \\
& Fear of failure & $0.23^{* * *}$ & 0.62 \\
Stepwise & Parenting & 0.05 & 0.88 \\
& Wealth & $0.21^{* * *}$ & 0.78 \\
& Age & 0.01 & 0.98 \\
Stepwise, Sex interactions & Sex & $0.10^{* *}$ & 0.93 \\
& Looks & $0.18^{* * *}$ & 0.70 \\
& Fear of failure & $0.23^{* * *}$ & 0.62 \\
& Wealth & $0.21^{* * *}$ & 0.80 \\
& Sex & -0.10 & 0.16 \\
& Looks & -0.10 & 0.09 \\
& Fear of failure & $0.23^{* * *}$ & 0.62 \\
& Wealth & $0.22^{* * *}$ & 0.79 \\
\hline
\end{tabular}

${ }^{*} p<0.05$.

${ }^{* *} p<0.01$.

${ }^{* * *} p<0.001$. 


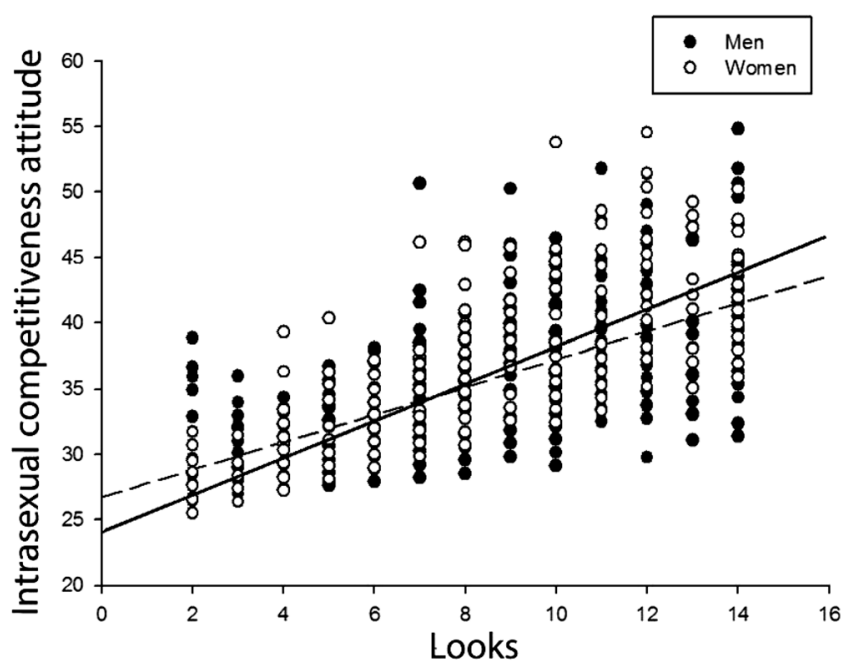

Figure 2. Scatterplot of the relationship between intrasexual competitiveness attitude and the subscale looks for men (dashed line) and women (solid line)

Table 4. Loadings from a higher order factor analysis of mate value subscales (note: $N=711$ )

\begin{tabular}{ccc}
\hline Variables & Factor 1 & Factor 2 \\
\hline Views from the opposite sex & $\mathbf{0 . 8 5}$ & -0.06 \\
Relationship history & $\mathbf{0 . 8 0}$ & -.01 \\
Sociality & $\mathbf{0 . 5 4}$ & -.02 \\
Parenting & 0.22 & 0.16 \\
Fear of failure & -0.09 & $\mathbf{0 . 8 7}$ \\
Looks & -0.28 & $\mathbf{0 . 5 5}$ \\
Wealth & -0.02 & $\mathbf{0 . 5 1}$ \\
\hline
\end{tabular}

sex in the regression analysis, and we used a stepwise method to fit the model. Accordingly with the previous results, the fitted model $\left(R^{2}=0.23, F(3,707)=69.05\right.$, $p<0.001)$ included the variables sex (beta $=-0.12$, $p=0.191)$, factor 2 (beta $=0.24, p=0.027$ ) and their interaction (beta $=0.29, \mathrm{p}=0.014)$. The interaction showed that factor 2 was positively related to intrasexual competitiveness attitude in both men and women, but the strength of this relationship was higher in women (see Figure 3).

\section{DISCUSSION}

The attitude to perceive same-sex interactions as competitive shows individual variation in humans (Buunk \& Fisher 2009). In the present study, we explored the relationship between self-perceived mate value, measured with the mate value components questionnaire, and intrasexual competitiveness attitude, in order to explain part of this variation. Our results indicated that self-perceived mate value influenced intrasexual competitiveness attitude, as prediction 1 proposed. However, when analyzing sexual differences in the relationship between traits that define mate value (through the mate value components subscales) and intrasexual competitiveness attitude, we obtained only partial support for predictions 2 and 3 .

We hypothesized that sex-differences in mate preferences would be useful for understanding the influence of self-perceived mate value over intrasexual competitiveness attitude in both sexes. However, our results indicated that, although mate preferences have been reported to show a clear sex-differentiated pattern in the trait choice (e.g., Buss 1989; Buss 2013), there was significant sex

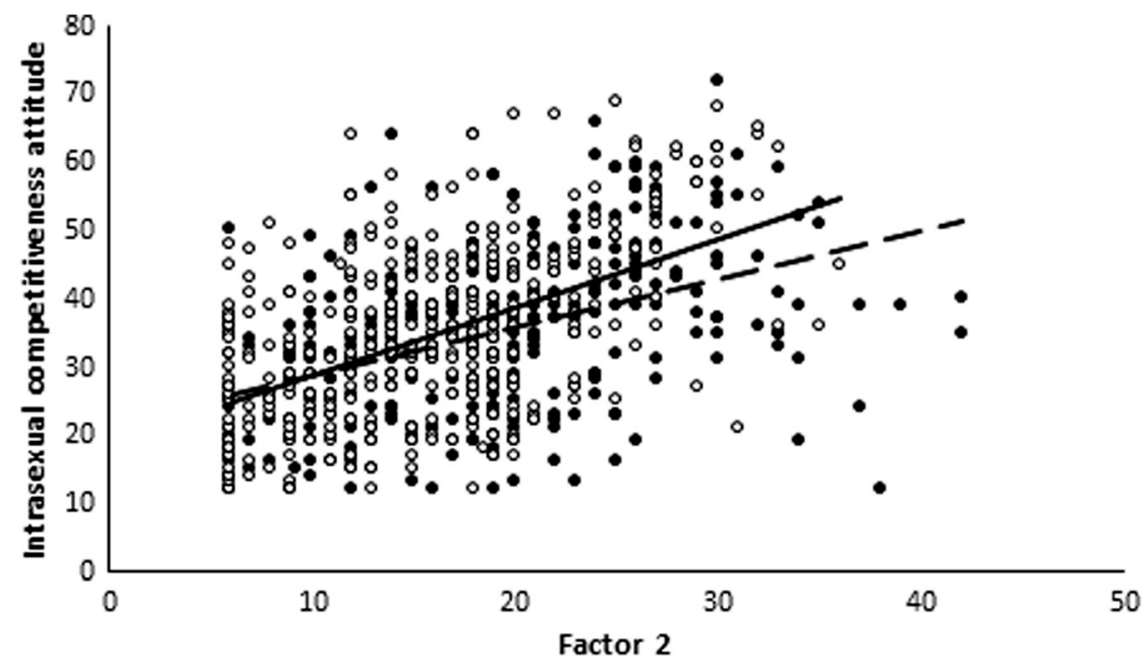

Figure 3. Scatterplot of the relationship between intrasexual competitiveness attitude and factor 2 for men (dashed line) and women (solid line) 
homogeneity in the influence of the psychological characteristics of mate value over intrasexual competitiveness attitude (at least for the Chilean population). Accordingly, the subscales of Wealth and Fear of Failure were two characteristics that had a similarly intense influence in intrasexual competitiveness attitude in both sexes. In contrast, the subscale Looks was the only trait that presented sexual dimorphism in the strength of its association with intrasexual competitiveness attitude (i.e., a stronger association was found in women than in men). These three subscales of mate value are part of the same factorial structure, which has specific attributes that are likely associated with attitudes of self-promotion and impression management.

Regarding Wealth subscale, we expected this variable to have a positive relationship with intrasexual competitiveness attitude in men but not in women, as economic resource is a trait preferred by women when searching for potential partners (Buss 1989; Buss 2013), possibly as a way to obtain a direct benefit for potential offspring. However, our results show a positive relationship for both sexes suggesting that Wealth is a relevant variable for understanding the attitude toward intrasexual competition in men and women. The Chilean socio-economic characteristics may partially explain the importance of this variable, especially in the case of women in which this relationship was unexpected. Chile has one of the high levels of socioeconomic disparity among members of the Organization for Economic Co-operation and Development (OECD; Gini index: 0.5 in ${ }^{\dagger}$ OECD, 2014). This has produced significant socioeconomic stratification and a high rate of social homogamy, i.e., marriage between members of the same socioeconomic level (e.g., Cartagena 2014; LópezRuiz, Esteve \& Cabré 2008, 2009). Accordingly, it is plausible to suppose that Chilean women attempt to expose their wealth or attempt to appear wealthy to attract men with the same or superior socioeconomic status. In addition, there is previous evidence reporting a positive effect of the socioeconomic status of parents over intrasexual competitiveness attitude of adolescents of both sexes (Buunk, Stulp \& Ormel 2014). Our results are in line with this finding, but future studies in more egalitarian or fewer homogamy societies are needed to assess whether Wealth becomes relevant for women in particular societies or is a more general pattern.

Fear of Failure was expected to be negatively related to intrasexual competitiveness attitude in men but not in women. Our results were unexpected, as we found a positive relationship for both sexes. The dimension of Fear of Failure can be better understood as an individual's tendency to feel apprehension about not being desired by a mate. In this regard, this association can be interpreted considering that individuals whose possess a more intense intrasexual competitiveness attitude are investing more time and energy in this issue and, therefore, they are more fearfully about the outcome of this competition. Another explanation that is not incompatible with this one considers the age of the participants as an important factor in

$\mp$ OCDE Organization for Economic Co-operation and Development. (2014). Society at a Glance 2014 Highlights: CHILE OECD Social Indicators. http://www.oecd.org/chile/OECD-SocietyAtaGlance2014-Highlights-Chile.pdf (Accessed on 4-16-2015). producing this result. Men and women in the sample were young, with ages near to or in their reproductive peak. Therefore, it is probable that anxiety and a lack of experience in the mating arena account for some of the factors that increased the effect of Fear of Failure. These arguments become important if we analyze the specific content of the items that comprise the subscale of Fear of Failure, which are mainly linked to dating (i.e., the commonly-experienced first stage of obtaining a mate, especially in young people). Therefore, for young people, negative feelings about the probability of failing in the mating arena (especially in dating) may be related to intrasexual competitiveness attitude in both sexes.

The Looks subscale was the unique dimension of mate value showing sexual dimorphism in its relationship with intrasexual competitiveness attitude. As predicted, for both sexes, Looks was positively related to intrasexual competitiveness attitude, but the relationship was more pronounced in women. This result is consistent with the extreme and cross-cultural relevance that female physical appearance has for both, intra and intersexual selection (Buss 2013; Fisher et al. 2008; Puts 2010). Several researchers have reported a relationship between physical attractiveness and intrasexual competition in women with different measures of attractiveness (e.g., Fisher et al. 2008; Singh 2002; Fernandez et al. 2014). Our results support the robust corpus of evidence regarding the relationship between attractiveness and sexual selection in both sexes, especially for women, but employing a self-perceived measure of physical attractiveness.

We clearly failed to find a relationship between intrasexual competitiveness attitude and the Parenting subscale in women. We predicted that the interest of women in having offspring would lead to an increased intrasexual competitiveness attitude. However, we only detected a significant effect of this subscale when considering correlational analyses, but this relationship disappeared when we fitted the regression analysis. Considering that our sample consisted on young women, this result may indicate that for young women other aspects of mate value, especially those linked to physical appearance, are most relevant in determining intrasexual competitiveness attitude than parenting. Whether the importance of parenting in determining intrasexual competitiveness attitude changes with age is an interesting question to tackle in future studies.

Finally, the result of the exploratory factor analysis on the 7 subscales of mate value indicates that Fear of Failure, Looks, and Wealth loaded together as one factor leading to the question of what do these three subscales have in common. Based on closer inspection of the content of the items included in the 3 subscales, we argue that these subscales not only encompass the self-assessment of traits but also include attitudes or motivations. Specifically, the 3 subscales reveal a preoccupation with potential mates' opinions about oneself, or, in a related vein, they may refer to mating tactics based on impression management. As a consequence, our results suggest that the psychological mechanisms underlying attitudes related to impression management and self-promoting are also related to the attitude of behaving intrasexual competitive. In addition, 
this relationship is very similar for both sexes indicating the importance of mutual courtship in both sexes, being choosy and competitive when searching for a mate (Stewart-Williams \& Thomas 2013).

To conclude, this study shows that mate value, as measured by the mate value components (Fisher et al. 2008), and intrasexual competitiveness attitude, as measured by the intrasexual competition scale (Buunk \& Fisher 2009), are positively associated. The subscales of Fear of Failure, Wealth, and Looks are positive predictors of intrasexual competitiveness attitude in both sexes. These three subscales may be indicative of a strategy based on the ostentation of traits through attitudes. All of this evidence allows us to argue that the psychological mechanisms that are involved in self-promotion and ostentation of traits involved in intersexual selection are promoting an attitude toward intrasexual competition in these same individuals. Future studies that incorporate a wide range of ages and cultures are necessary to sustain the relevance of mate value and their subscales to explain intrasexual competitiveness attitude.

Acknowledgments: This research was supported by funds from both FONDECYT projects: 1140234 and 11181293 from the Government of Chile.

\section{REFERENCES}

Archer, J. (2009a). Does sexual selection explain human sex differences in aggression? Behavioral and Brain Sciences, 32, 249-266. doi: 10.1017/S0140525X09990951

Archer, J. (2009b). The nature of human aggression. International Journal of Law and Psychiatry, 32, 202-208. doi: 10.1016/j.ijlp.2009.04.001

Berglund, A., Bisazza, A., \& Pilastro, A. (1996). Armaments and ornaments: an evolutionary explanation of traits of dual utility. Biological Journal of the Linnean Society, 58, 385399. doi: 10.1111/j.1095-8312.1996.tb01442.x

Brase, G. L., \& Guy, E. C. (2004). The demographics of mate value and self-esteem. Personality and Individual Differences, 36, 471-484.

Buss, D. M. (1989). Sex differences in human mate preferences: Evolutionary hypotheses tested in 37 cultures. Behavioral and Brain Sciences, 12, 1-14. doi: 10.1017/ S0140525X00023992

Buss, D. M. (2013). Sexual jealousy. Psihologijske Teme, 22, 155-182.

Buunk, A., \& Fisher, M. (2009). Individual differences in intrasexual competition. Journal of Evolutionary Psychology, 7, 37-48. doi: 10.1556/JEP.7.2009.1.5

Buss, D. M., \& Schmitt, D. P. (1993). Sexual strategies theory: an evolutionary perspective on human mating. Psychological Review, 100, 204-232.

Buunk, A. P. (2017). There is more: Intrasexual competitiveness, physical dominance, and intrasexual collaboration. Behavioral and Brain Sciences, 40, e23. doi: 10.1017/ S0140525X16000443
Buunk, A. P., Stulp, G., \& Ormel, J. (2014). Parental social status and intrasexual competitiveness among adolescents. Evolutionary Psychology, 12, 147470491401200511. doi: $10.1177 / 147470491401200511$

Cartagena, J. (2014). Is assortative mating a limitation for intergenerational mobility? The role of the Chilean privatization educational reform. Paper presented at the Sixth International Workshop on Applied Economics of Education, Catanzaro, Italy.

Cashdan, E. (1998). Are men more competitive than women? British Journal of Social Psychology, 37, 213-229. doi: 10.1111/j.2044-8309.1998.tb01166.x

Darwin, C. (1871). The descent of man, and selection in relation to sex. London: Murray.

Dormann, C. F., Elith, J., Bacher, S., Buchmann, C., Carl, G., Carré, G., \& Lautenbach, S. (2013). Collinearity: a review of methods to deal with it and a simulation study evaluating their performance. Ecography, 36, 27-46. doi: 10.1111/ j.1600-0587.2012.07348.x

Edlund, J. E., \& Sagarin, B. J. (2010). Mate value and mate preferences: An investigation into decisions made with and without constraints. Personality and Individual Differences, 49, 835-839. doi: 10.1016/j. paid.2010.07.004

Edlund, J. E., \& Sagarin, B. J. (2014). The Mate Value Scale. Personality and Individual Differences, 64, 72-77. doi: 10.1016/j.paid.2014.02.005

Feingold, A. (1992). Gender differences in mate selection preferences: A test of the parental investment model. Psychological Bulletin, 112, 125-139. doi: 10.1037/00332909.112.1.125

Fernandez, A. M., Muñoz-Reyes, J. A., \& Dufey, M. (2014). BMI, age, mate value, and intrasexual competition in Chilean women. Current Psychology, 33, 435-450. doi: 10.1007/ s12144-014-9221-x

Fernández, A. M., Muñoz-Reyes, J. A., Dufey, M., Buccioni, G., \& Cid, V. (2015). Adaptación del Cuestionario de Componentes del Valor de Pareja al contexto chileno [Adaptation of the Mate Value Questionnaire to the Chilean context]. Revista Iberoamericana de Diagnóstico y Evaluación Psicológica, 40, 94-102.

Fisher, M. L. (2004). Female intrasexual competition decreases female facial attractiveness. Proceedings of the Royal Society B: Biological Sciences, 271, S283-S285. doi: 10.1098/ rsbl.2004.0160

Fisher, M., \& Cox, A. (2009). The influence of female attractiveness on competitor derogation. Journal of Evolutionary Psychology, 7, 141-155. doi: 10.1556/ JEP.7.2009.2.3

Fisher, M., Cox, A., Bennett, S., \& Gavric, D. (2008). Components of self-perceived mate value. Journal of Social, Evolutionary, and Cultural Psychology, 2, 156-168. doi: 10.1037/h0099347

Frederick, D. A., \& Haselton, M. G. (2007). Why Is Muscularity Sexy? Tests of the Fitness Indicator Hypothesis. Personality and Social Psychology Bulletin, 33, 1167-1183. doi: 10.1177/0146167207303022

Grammer, K., Fink, B., Møller, A. P., \& Thornhill, R. (2003). Darwinian aesthetics: sexual selection and the biology of beauty. Biological Reviews, 78, 385-407. doi: 10.1017/ S1464793102006085 
Hill, A. K., Hunt, J., Welling, L. L. M., Cárdenas, R. A., Rotella, M. A., Wheatley, J. R., Dawood, K., Shriver, M. D. \& Puts, D. A. (2013). Quantifying the strength and form of sexual selection on men's traits. Evolution and Human Behavior, 34, 334-341. doi: 10.1016/j.evolhumbehav.2013.05.004

Kirsner, B. R., Figueredo, A. J., \& Jacobs, W. J. (2003). Self, friends, and lovers: structural relations among Beck Depression Inventory scores and perceived mate values. Journal of Affective Disorders, 75, 131-148. doi: 10.1016/ S0165-0327(02)00048-4

Landolt, M. A., Lalumière, M. L., \& Quinsey, V. L. (1995). Sex differences in intra-sex variations in human mating tactics: An evolutionary approach. Ethology and Sociobiology, 16, 3-23. doi: 10.1016/0162-3095(94)00012-V

Little, A. C., Jones, B. C., \& Burriss, R. P. (2007). Preferences for masculinity in male bodies change across the menstrual cycle. Hormones and Behavior, 51, 633-639. doi: 10.1016/j. yhbeh.2007.03.006

López-Ruiz, L. A., Esteve, A., \& Cabré, A. (2008). Distancia social y uniones conyugales en América Latina. Revista Latinoamericana de Población, 1, 47-71.

López-Ruiz, L. A., Esteve, A., \& Cabré, A. (2009). Uniones consensuales y matrimonios en América Latina: ¿dos patrones de homogamia educativa? Papeles de Población, 15, 09-40.

Marcinkowska, U. M., Jasienska, G., \& Prokop, P. (2017). A Comparison of Masculinity Facial Preference Among Naturally Cycling, Pregnant, Lactating, and Post-Menopausal Women. Archives of Sexual Behavior. doi: 10.1007/s10508-017-1093-3

Muñoz-Reyes, J. A., Fernández, A. M., Flores-Prado, L., Guerra, R., \& Turiégano, E. (2015). Fighting ability influences mate value in late adolescent men. Personality and Individual Differences, 80, 46-50. doi: 10.1016/j.paid.2015.02.026
Muñoz-Reyes, J. A., Gil-Burmann, C., Fink, B., \& Turiegano, E. (2012). Physical strength, fighting ability, and aggressiveness in adolescents. American Journal of Human Biology, 24, 611-617. doi: 10.1002/ajhb.22281

Puts, D. A. (2010). Beauty and the beast: mechanisms of sexual selection in humans. Evolution and Human Behavior, 31, 157-175. doi: 10.1016/j.evolhumbehav.2010.02.005

Puts, D. (2016). Human sexual selection. Current Opinion in Psychology, 7, 28-32. doi: 10.1016/j.copsyc.2015.07.011

Roberts, S. C., \& Little, A. C. (2008). Good genes, complementary genes and human mate preferences. Genetica, 132, 309-321. doi: 10.1007/s10709-007-9174-1

Singh, D. (2002). Female mate value at a glance: Relationship of waist-to-hip ratio to health, fecundity and attractiveness. Neuroendocrinology Letters, 23, 81-91.

Stewart-Williams, S., \& Thomas, A. G. (2013). The Ape That Thought It Was a Peacock: Does Evolutionary Psychology Exaggerate Human Sex Differences? Psychological Inquiry, 24, 137-168. doi: 10.1080/1047840X.2013.804899

Sznycer, D., Al-Shawaf, L., Bereby-Meyer, Y., Curry, O. S., De Smet, D., Ermer, E., . . . Tooby, J. (2017). Cross-cultural regularities in the cognitive architecture of pride. Proceedings of the National Academy of Sciences, 114, 1874-1879. doi: 10.1073/pnas.1614389114

Vaillancourt, T. (2013). Do human females use indirect aggression as an intrasexual competition strategy? Philosophical Transactions of the Royal Society of London B: Biological Sciences, 368, 20130080. doi: 10.1098/ rstb.2013.0080

Wilson, M., \& Daly, M. (1985). Competitiveness, risk taking, and violence: The young male syndrome. Ethology and Sociobiology, 6, 59-73. doi: 10.1016/0162-3095(85)90041-X 